\title{
Estresse e desempenho nas matérias básicas: variáveis relevantes*
}

\author{
Geraldina Porto Witter ${ }^{1}$ \\ Pontifícia Universidade Católica de Campinas
}

\begin{abstract}
Fornece uma perspectiva geral das principais variáveis presentes na relação desempenho em aprendizagem e ambientes estressores na e for $a$ da escola. A experiência de estresse em relação ao desempenho acadêmico é influenciada por vários fatores contextuais e pessoais. É possível reduzir o estresse negativo usando estratégias para enfrentar as variáveis estressantes. É relevante desenvolver programas de prevenção de estresse nos atores escolares.

Palavras-chave: estresse acadêmico; desempenho acadêmico; variáveis estressantes.
\end{abstract}

\begin{abstract}
Stress and performance in basic academic disciplines: relevant variables

Provides a general account of the main variables presented in the relation of learning performance and stressful enviroments in and out of school. The experience of stress in relation to academic performance is influenced by a number of contextual and personal factors. It's possible to reduce negative stress using strategies of coping with stressful variables. It is relevant to develop programs to prevent stress in the schools setting.
\end{abstract}

Key words: academic stress; academic performance; stressful variables.

O vocábulo estresse designa um conjunto de respostas, abertas e encobertas, de caráter psico-fisiológico, que se instala processualmente quando contingências ambientais eliciam respostas emocionais e cognitivas, positivas e negativas, para as quais os sujeitos nem sempre estão ou se sentem preparados para apresentar, ou seja, para enfrentar as contingências, de modo satisfatório (reforçador para eles). Estas respostas podem incluir reações biológicas adversas que tendem a se agravar com o tempo, caso o sujeito não aprenda como lidar com as contingências estressantes, isto é, não consiga equilibrar a demanda com sua capacidade. (Selye, 1965; Fisher, 1994).

\footnotetext{
* Trabalho apresentado em mesa-redonda do I Simpósio sobre estresse e suas implicações. PUC-Campinas, Campinas, 1996.

1. Professora doutora na Pós-Graduação em Psicologia da PUC-Campinas. Endereço para correspondência: Departamento de Pós-Graduação em Psicologia, Rua Waldemar Cesar da Silveira, 105, Swift, CEP 13045-270, Campinas, SP.
}

As contingências responsáveis pelo desencadeamento e manutenção do estresse são chamadas estressoras e podem estar presentes no lar, na escola, no clube esportivo, no ambiente de trabalho ou em qualquer outro espaço. Também se fazem presentes ao longo da vida das pessoas, da infância à velhice.

Vale lembrar que o número de crianças com sintomas de estresse vem crescendo, conforme Lipp et all (1995), possivelmente porque fatores geradores de estresse venham se tornando mais presentes e potentes já em etapas iniciais da vida. É possível que o conhecimento ampliado gradativamente na área já esteja viabilizando detectar o problema mais precocemente. Também é provável que o constatar desse crescimento tenha ocorrido por já se dispor de mais pesquisadores atentos ao problema.

A escola é um ambiente onde essas contingências podem se fazer presentes com muita freqüência, com diversos estressores institucionalizados sem que haja o devido preparo para os 
alunos lidarem com essas situações. Agentes estressores aparecem desde a entrada da criança na escola até a pós-graduação, ou seja, do mais baixo ao mais alto nível de escolarização. Os alunos raramente são preparados para controlar ou evitar o estresse em tais situações.

A preocupação em preparar a criança para a entrada na escola, mesmo a pré-escola, se fez cada vez mais presente desde os anos $60 \mathrm{e}$ pode ser uma forma de reduzir a força dos estressores potenciais desde o início da escolarização. As escolas devem manter programas para este fim e eles devem envolver os pais, posto que a família em suas relações com a vida acadêmica também pode ser fonte de estresse para a criança.

Há pais que ainda apresentam a escola como lugar de punição, de castigo; há professores estressados; há docentes que não sabem como reduzir o impacto das contingências estressoras da escola e que muitas vezes atuam de modo a fortalecê-las. Essas considerações podem e se estendem por todos os níveis de escolaridade. Os chamados exames de qualificação e as defesas de dissertações e teses são contingências estressoras que atuam sobre os pós-graduandos desde o início do curso e podem desencadear um processo que pode levar o aluno à exaustão.

Certamente, o vestibulando é um estudante particularmente sujeito ao estresse em decorrência dos problemas a enfrentar para aprender e superar a barreira do exame, como também da pressão exercida pela família que estabelece e explicita estimativas de êxito para ele.

Como exemplo, pode ser lembrado o trabalho de Santos e colaboradores (1996) enfocando o estresse em 23 pós-graduandos. A maioria $(91,3 \%)$ considerou o curso estressante, oscilando entre "excessivo" (47,8\%) e razoável $(43,5 \%)$.

Mas o estresse não é apanágio dos alunos; pode aparecer em professores, em adminis- tradores e em outros funcionários tanto em decorrência de situações intramuros da escola como em decorrência de variáveis externas. Ex: a transferência de escola por determinação superior sem atender a motivação e ao previsto pelo docente para sua vida profissional, como aconteceu no estado de São Paulo, no ano corrente (1995).

Neste quadro é particularmente relevante o estresse de professores, já que interfere diretamente nas suas relações interpessoais com os alunos e no processo ensino-aprendizagem. Justifica-se, desta forma, o investimento de pesquisa envolvendo esse profissional. Como exemplo, pode ser mencionado aqui o trabalho de Soyibo (1994), que encontrou entre professores de ciência graus variados de estresse em decorrência de variáveis como gênero, localização da escola, experiência de ensino ou assunto a ensinar. A pesquisa de Okebukola \& Jegede (1992) mostrou como principais fatores geradores de estresse em professores de ciências: dificuldades para obter equipamentos; tópicos do programa; tempo para cumprir o programa; ensinar o que não foram treinados a fazer e currículo novo.

Heinhold (1996), ao rever a produção sobre estresse de docentes, encontrou como estressores: fatores administrativos; alunos; condições de trabalho; fatores pessoais; colegas; pais de alunos; imagem profissional negativa; falta de qualificação e de preparo técnico do professor.

Martins, Seleguini e Moura (1996) também verificaram que $85 \%$ dos professores de psicologia do $2^{\circ}$ grau que foram entrevistados consideravam a profissão estressante.

A Fig. 1 mostra que o estresse na escola decorre de contingências internas a ela, assim como do ambiente externo, o que pode-se intuir do já exposto. 


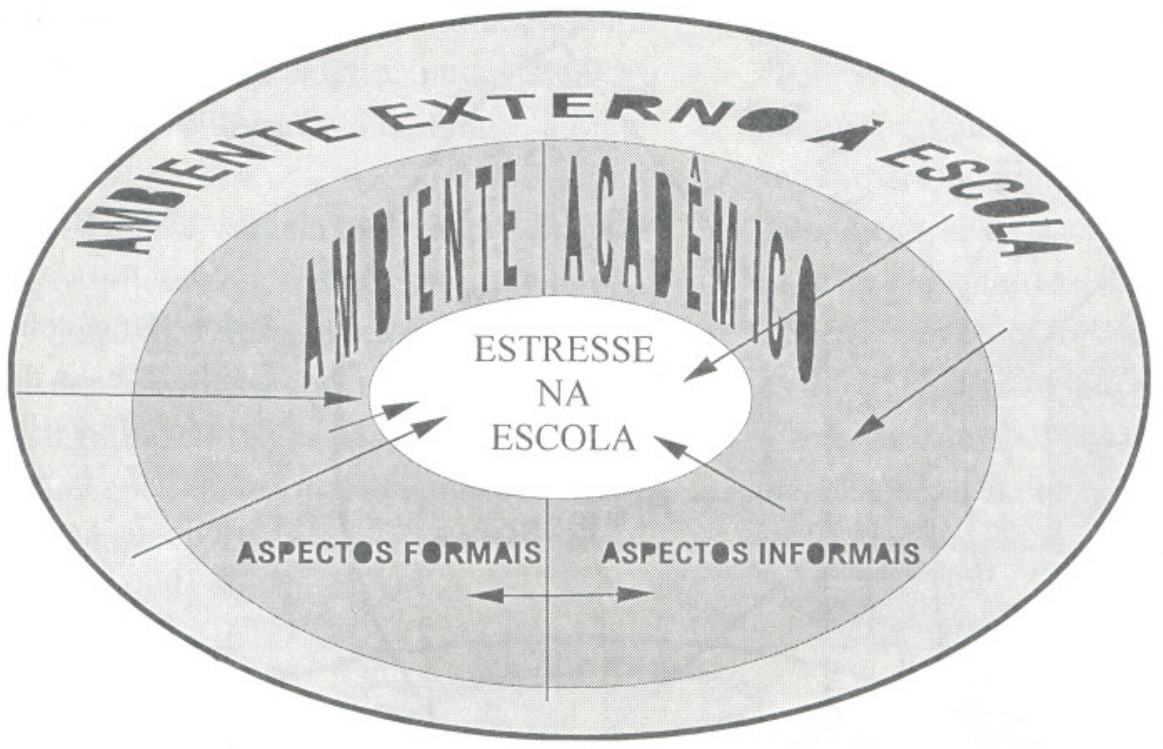

Figura 1. Contigências geradoras de estresse na escola

As contingências estressoras externas à escola podem potencializar as internas aumentando a probabilidade de ocorrência ou a intensidade de estresse nos atores da escola. Por exemplo, o professor que recebe baixo salário tem freqüentes exigências para melhorar seu desempenho por parte da sociedade (críticas em jornais, periódicos, de pais etc.) sem que lhe sejam dadas condições para atuar adequadamente, tendo classes numerosas, não tendo recursos e formação para superar as barreiras. Nessas condições, ele é um forte candidato a estresse.

No trabalho de Martins, Seleguini e Moura (1996) as variáveis acadêmicas alcançaram $62 \%$ dentre os fatores estressantes; classes numerosas ficou com $77 \%$; salário e desvalorização social com $92 \%$; falta de recursos materiais e didáticos com $85 \%$ de indicações feitas pelos docentes.

Variáveis externas como contingências de extrema pobreza ou conflitos podem gerar estresse em estudantes, como verificou Mulatu (1995), em pesquisa feita com estudantes de 6 a 11 anos, da Etiópia. Todavia, em condições não extremadas, Vilela (1995), no Brasil, não encontrou diferenças de estresse atribuível a classe social, mas com índices que atingem mais de $60 \%$ dos alunos de escolas públicas e particulares.

No ambiente acadêmico há aspectos formais e informais que geram condições propícias ao surgimento do estresse. De fato, todo o currículo escolar (não só o rol de disciplinas) pode ser gerador de estresse.

Entre os aspectos informais do currículo acadêmico estão as relações interpessoais. A criança com habilidades sociais aquém do esperado para sua faixa etária e de escolaridade pode não alcançar os padrões cobrados pelos adultos e colegas na escola e apresentar problemas, como redução ou rebaixamento de seu autoconceito, estresse, entre outros (Merrell, Cedeno e Johnson, 1993; Bandura, 1986).

No presente texto enfatizar-se-ão os aspectos formais do ambiente acadêmico que geram, mantêm ou intensificam o estresse dos atores da escola, especialmente o aluno. Mas é preciso ter sempre presente a influência constante das contingências informais do ambiente acadêmico e mesmo do ambiente externo à escola.

A Fig. 2 representa as principais variáveis que podem estabelecer contingências estressoras no ambiente da escola.

Direção, administração, burocracia, professores, grêmios e grupos, ambiente físico e mesmo os alunos podem estabelecer condições de serem agentes estressores tanto de docentes 


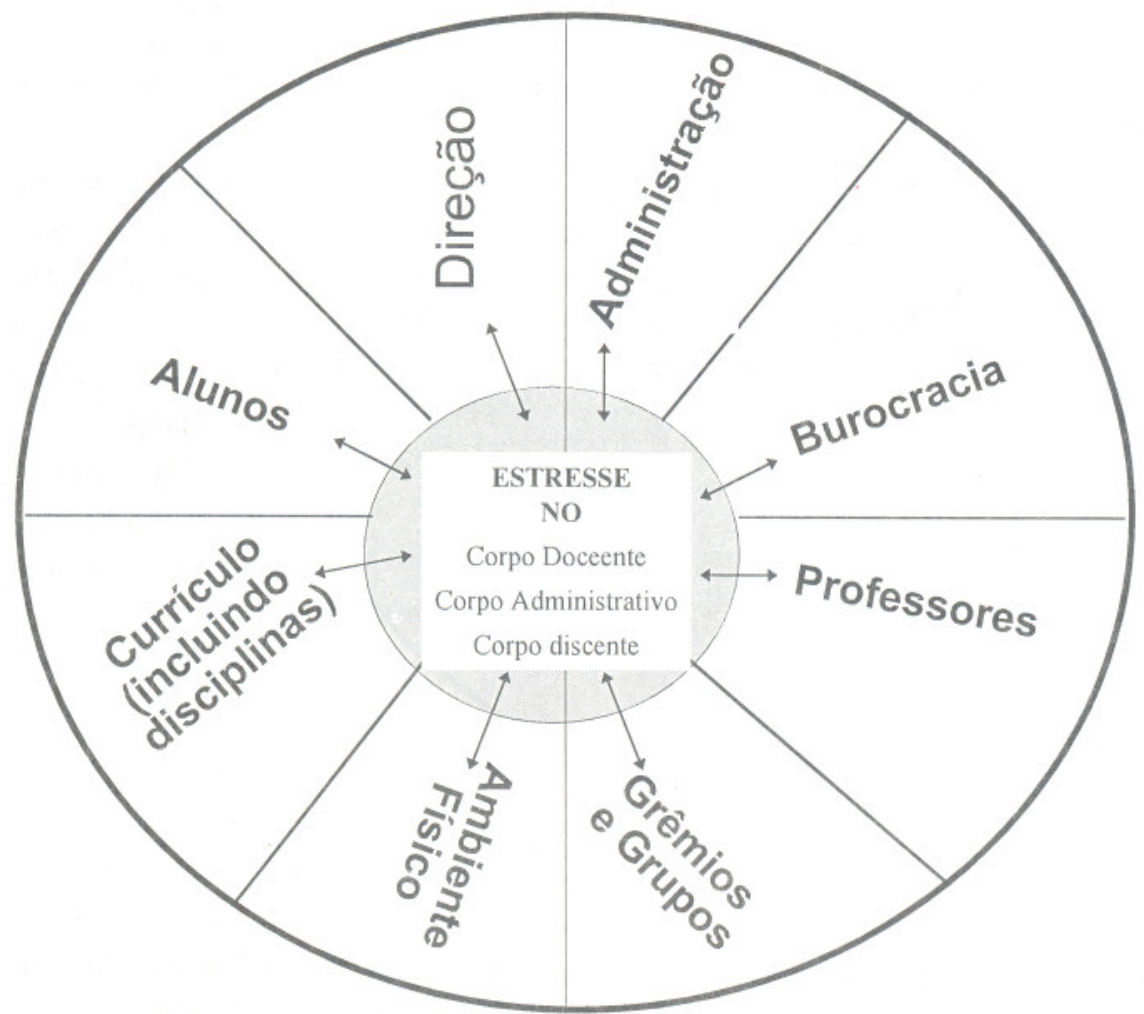

Figura 2. Variáveis que podem estabelecer contingências estressoras no âmbito da escola

Infelizmente, há carência de pesquisas sobre esses estressores tanto no Brasil como no exterior. Uma consulta à base de dados Psyclit, cobrindo o período de janeiro de 1990 a junho de 1996, em busca de artigos sobre estresse e aprendizagem das disciplinas básicas (leitura, escrita, aritmética e ciências), resultou em

como do corpo administrativo, como de alunos. $\mathrm{O}$ currículo mal organizado, inadequado aos alunos e às necessidades sociais, também é fator que pode gerar estresse.

Como exemplo, pode ser retomado o trabalho de Santos e colaboradores (1994), na pesquisa com pós-graduandos já referida, em que se verificou que a categoria mais estressante foi a relativa a questões acadêmicas $(70 \%)$, na qual as subcategorias mais freqüentes foram: pressão dos órgãos mantenedores $(35,8 \%) \mathrm{e}$ exigências institucionais (30,7\%).

$\mathrm{O}$ estresse do aluno associado ao ensino de disciplinas específicas como a leitura, a escrita, as ciências, a matemática pode decorrer de estressores extrínsecos ou intrínsecos às mesmas; por efeito de variáveis do próprio aluno e de variáveis externas que atuam quer sobre as disciplinas, quer sobre o aluno, quer ainda no próprio estresse manifestado pelo estudante. apenas 37 referências, sendo que uma delas dizia respeito ao estresse profissional, ou seja, como variável que levava assistentes sociais a abandonarem a profissão (Miller, 1991), portanto, ficando-se apenas com 36 referências. Estes resultados indicam baixa produtividade na área.

Destes 36 artigos, a maioria $(\mathrm{N}=24)$ enfoca o adulto sendo a seguinte a distribuição quanto a sujeitos: universitários - 39\%; professores - $11 \%$; outros adultos - 17\%; crianças $17 \%$; adolescentes - $11 \%$, e um trabalho com excepcionais sem especificação de idade (Margolis, 1990). Algumas pesquisas enfocaram concomitantemente mais de um tipo de sujeitos.

Quanto às disciplinas básicas enfocadas, também houve estudo em que mais de uma mereceu a atenção dos pesquisadores. A distribuição encontrada foi: $36 \%$ dos trabalhos estudaram a Leitura; $30 \%$, a Matemática; $17 \%$ enfocaram a aprendizagem de Ciências e 14\% a da Escrita. 
Esses dados mostram a tendência dos estudos da área, nos quais se trabalha mais freqüentemente com o adulto, notadamente o universitário, e enfocando a Leitura ou a Matemática.

A Fig. 3 apresenta uma síntese das relações que influenciam o estresse do aluno.

Entre os estressores externos, a família, notadamente os pais, podem constituir-se em componentes relevantes para tornar o ensinoaprendizagem de uma matéria uma contingência estressante.

vários aspectos do ensino-aprendizagem da mesma e acabar por torná-lo fonte de estresse.

As variáveis do aluno que podem associar-se à apresentação de estresse incluem a motivação para a aprendizagem da disciplina, a autopercepção de seu potencial para aprendê-la e seu desempenho real na mesma. Uma desarticulação entre estes três componentes é suficiente para gerar estresse e outros problemas de comportamento (Bandura, 1986) que, como conseqüência, resultarão em baixo desempenho acadêmico. Entretanto, o domínio de estratégias para enfrentar situações estressantes poderá fazer com que o aluno tenha êxito, ou que não chegue a um nível prejudicial de estresse, ou mesmo que o supere.

Entre as variáveis geradoras de estresse que estão mais associadas às disciplinas básicas estão: ima-

Pais matemáticos, docentes de línguas e cientistas podem tornar-se figuras estressantes para a aprendizagem destas matérias pelos seus filhos.

Convém lembrar que, em contrapartida, os pais podem dar uma contribuição única e insuperável na formação de resistência, na redução da vulnerabilidade e na capacitação de seus filhos para lidarem com o estresse, como lembram Lipp e Malagris (1995). É preciso orientá-los para que melhor exerçam este potencial.

$\mathrm{O}$ fato de a sociedade considerar que aprender uma dada disciplina requer habilidades e capacidades superiores pode influir em gem social da disciplina; prestígio da disciplina na escola, professor da matéria; metodologia de ensino utilizada, sistema de avaliação e as dificuldades/limitações específicas da disciplina.

Já se fez menção aqui ao fato de a imagem social da disciplina poder ser um gerador de estresse.

O prestígio que a disciplina tem na escola, incluindo-se o espaço que ocupa no currículo, também pode se tornar estressor, pois tende a consumir mais tempo, a exigir mais, a esperar mais e melhor desempenho do aluno, a ter uma cobrança interna e externa mais potente. Além disso, há disciplinas que adquirem o status de 
"difíceis", de responsáveis pela maioria das reprovações tornando-se assim estressoras quando, de fato, não precisariam ser.

Isso associa-se ao professor que, de certa forma, antipsíquica e antipedagogicamente muitas vezes recorre apenas a técnicas aversivas para controlar a classe; outras vezes, ele próprio está estressado, criando assim condições estressantes ao longo do processo ensinoaprendizagem de sua disciplina. O que é pior, o aluno associa essas contingências à disciplina $\mathrm{e}$ as generaliza para a aprendizagem da mesma nos anos subseqüentes, até mesmo por toda sua vida em relação àquela matéria.

A metodologia de ensino, os procedimentos, as estratégias e os materiais de ensino quando inadequados ou usados de forma inapropriada podem gerar dificuldades para o aluno e se tornarem estressores. Certamente, procedimentos individualizados de ensino de caráter não punitivo, como por exemplo, os empregados no Método Keller, ou a instrução Programada, tendem a reduzir ao mínimo as probabilidades de um estresse prejudicial ao desempenho acadêmico. Entretanto, dispõe-se de poucos materiais e nem todos os docentes estão aptos a empregá-los. Por outro lado, procedimentos que não levam em consideração as características pessoais dos alunos tendem a ser estressores.

Por exemplo, a pesquisa de Walczyk (1995) mostrou que há prejuízo no desempenho em leitura (eficiência e compreensão) de adultos quando a atividade de ler é exercida em condições de alta pressão de tempo, considerando que isto ocorre porque a pessoa não tem condições para pôr em ação os mecanismos compensatórios para superar o estresse gerado pela pressão.

O sistema de avaliação também pode parecer ao aluno uma ameaça e gerar estresse, cabendo à escola e ao professor a análise de quanto a avaliação está gerando comportamen- tos adequados e inadequados e redirecioná-la para que atinja o melhor desempenho acadêmico esperado.

O conteúdo específico das várias disciplinas apresentạ também pontos críticos a serem superados no processo ensino-aprendizagem. Estes pontos podem gerar estresse tanto no aluno como no professor. O professor pode não se julgar suficientemente apto, ou desconhecer estratégias, ou não gostar daquele tópico ou mesmo daquela disciplina. Estas variáveis poderão ser estressantes para ele e, refletindo no processo ensino-aprendizagem, também gerar estresse em seus alunos, levando a pouco aproveitamento de suas aulas.

Em toda disciplina há conhecimentos a serem assimilados que dependem de aprendizagens anteriores. Quando os alunos não as possuem, aprender novas informações torna-se por si só uma tarefa estressante. Em um sistema educacional em que os programas não são vencidos ao longo do ano, em que se começa o ano seguinte como se o aluno realmente dominasse o programa dos anos anteriores, a probabilidade de os temas novos tornarem-se estressantes também cresce.

Os estressores externos à escola, ou aqueles internos à instituição, relativos às disciplinas acadêmicas ou aos atores da vida escolar raramente atuam de forma isolada. Combinações dos mesmos costumam se fazer presentes quando ocorre estresse prejudicando o desempenho do aluno.

Como exemplo, pode ser lembrada a pesquisa de Koretz e col. (1994) em que se verificou que a baixa qualidade e a avaliação de aproveitamento de escolares em escrita e aritmética estão associadas com estresse e variáveis estressoras como pressão de tempo e variação na atuação dos docentes.

Outro aspecto a considerar é que esses estressores não atuam da mesma forma sobre todos os agentes e atores da escola. Um docente 
pode ter um comportamento estressante para um aluno e não ser um estressor para a maioria da classe; pode gerar estresse ao lecionar matemática e não o fazer na aula de leitura.

Há diferenças individuais no responder a variáveis estressantes. Isto foi demonstrado, por exemplo, na pesquisa de Walsh, Wilding e Eysinck (1994), os quais constataram que os diferentes tipos de resposta ao estresse estão relacionados com diferenças individuais, formando padrões complexos, dificilmente medidos por um só instrumento ou um só tipo de medida.

Embora um certo grau de estresse seja relevante e mesmo necessário para a sobrevivência e o envolvimento com a tarefa (Fisher, 1994; Reinhold, 1996), são necessárias medidas para prevenir seu avanço a níveis prejudiciais e mesmo terapia quando esses níveis já se instalaram.

Já se fez menção aqui a atuações e estratégias que podem reduzir ou eliminar o poder de estressores, como é o caso de uso de tecnologias apropriadas de ensino, escolha de material didático compatível com as características do aluno e suas necessidades de desenvolvimento, entre outras.

É relevante ensinar a todos os atores da escola e a todos os que com ela se relacionarem a trabalhar com o estresse envolvendo a aprendizagem das disciplinas acadêmicas. Por vezes, se requer pouco para se ter resultados satisfatórios. Assim é que Omizo e Omizo (1990) verificaram que o simples fato de aprender a detectar quais são os estressores é suficiente para ajudar a criança.

Além disso, já se dispõe de tecnologia para a superação de estresse nas escolas, cuja eficiência vem sendo demonstrada há décadas, faltando apenas uma melhor divulgação e um corpo de psicólogos na escola capazes de implementar programas de prevenção, atuando interdisciplinarmente com outros profissionais da instituição, notadamente os professores.
Exemplo das pesquisas dentro da preocupação de teste de tecnologia para trabalhar com o problema aqui enfocado é o trabalho de Schneider e Nevid (1993) que demonstra a eficiência da dessensibilização sistemática na redução de estresse em situações envolvendo desempenho em matemática.

Certamente, com adequada tecnologia, bom planejamento e capacitação docente, todos os fatores estressantes que podem prejudicar o desempenho acadêmico dos alunos podem ser reduzidos ou praticamente eliminados. Com o ensino de estratégias de manejo e de controle do estresse para professores, pais, administradores escolares e alunos muito se poderia fazer em termos de prevenção do fracasso escolar, de problemas de aprendizagem e mesmo do não gostar de algumas disciplinas básicas. Esta é uma área de atuação em que, com baixo custo, muitos se beneficiaram e haveria melhoria substancial no processo de ensino-aprendizagem.

\section{Referências}

Bandura, A. (1986). Social foundations of thought and action: a social cognitive theory. New Jersey: Printice-Hall.

Fisher, S. (1994). Stress in Academic Life: the mental assembly line. Buckinghan: Open University Press.

Koretz, D.; Stcher, B.; Klein, S. \& McCaffrey, D. (1994). The Vermont Portfolie Assessment Program: findings and implications. Educational Measurement Issues and Practice, 13 (3): 5-16.

Lipp, M.N. \& Malagris, L.N. (1995). Manejo do estresse. In: B. Rangé (org.). Psicoterapia comportamental e cognitiva e de transtornos psiquiátricos. Campinas: Editorial Psy II.

Lipp, M.N.; Souza, P.A.E.; Romano, F.S.A. \& Covolan, M.A. (1994). Como enfrentar o estresse infantil. Campinas: Ícone. 
Margolis, H. (1990). Relaxation training: a promissing approach for helping exceptional learners. International Journal of Disability, Development and Education, 37 (3): 215-234.

Martins, R. de C.; Seleguini, L. \& Moura, M. (1996). Estresse ocupacional em professores de psicologia. Anais do I Simpósio sobre estresse e suas implicações. Campinas: PUCCAMP, 109.

Merrell, K.W.; Cedeno, C.J. \& Johnson, E.R. (1993). The relationship between social behavior and self-concept in school settings. Psychology in the Schools, 30 (4): 293-98.

Miller, L.S. (1991). The relationship between social support and bournot: clarification and simplification. Social Work Research and Abstracts, 27 (1): 34-7.

Mulatu, M.S. (1995). Prevalency and risk factors of psychopathology in Ethiopial Children. Journal A.M.ACAD. Child and adolescence Psychiatry, 34 (1): 101-20.

Okebukda, P.A. \& Jegede, O.J. (1992). Survey of factors that stress science teachers and an examination of coping strategies. Science Education, 76 (2): 199-210.

Omizo, M.M. \& Omizo, S.A. (1990). Children and stress: using a phenomenological approach. Elementary School: Guidance and Counseling, 21 (1): 30-36.

Reinhold, H. H. (1994). O estresse do professor primário. Anais do I Simpósio sobre estresse e suas implicações. Campinas: PUCCAMP, 54-61.

Santos, A. M. dos; Martinez, A.; Baptista, M.N.; Miglioli, F. A. \& Lipp, M.N. Níveis de estresse em pós-graduandos. Anais do I Simpósio sobre estresse e suas implicações. Campinas: PUCCAMP, 108.

Schneider, W.J. \& Nevid, J.S. (1993). Overcoming math anxiety: a comparison of stress inoculation training and systematic disensitization. Journal of College Student Development, 34 (4): 283-88.

Selye, H. (1975). Estresse a tensão da vida. Trad. do original inglês, de 1965, por F. Branco. São Paulo: IBRASA.

Soyibo, K. (1994). Occupational stress factors and coping strategies among Jamaican high-school science teachers. Research in Science and Technological Education, 12 (2): 187-92.

Vilela, M. (1995). Sintomas e fontes de estresse: amostra de escolares do $1^{\circ}$ grau. Dissertação de Mestrado apresentada ao Instituto de Psicologia da PUCCAMP, Campinas.

Walezyk, J.J. (1995). Testing a compensatory-encoding model. Reading Research Quarterly, 30 (3): 396-408.

Walsh, J.J.; Wilding, J.M. \& Eysenck, M.W. (1994). Stress responsivity: the role of individual differences. Personality and individual Differences, 16 (3): 385-94. 